\title{
To Determine Level of Post Traumatic Stress Faced By Adolescent Children with Chronic Illness
}

\author{
Mridula.C.Jobson $^{1 *}$, Dr. R. Subhashini ${ }^{2}$
}

\section{ABSTRACT}

Background: Chronic Illness is disorders or diseases that compromise well-being, either temporarily or chronically. Identifying related risk factors is of theoretical and practical relevance. It helps to understand psychosocial consequences of chronic diseases and provide valuable information for clinicians regarding who should be screened for what kind of problems. These children undergo a silent development of stress which occur Post Trauma. Post Traumatic Stress (intrusive memories, avoidance, and distress) is a condition of persistent mental and emotional stress occurring as a result of injury or severe psychological shock. Aim and Objective: To determine level of post traumatic stress faced by adolescent children with chronic illness. Samples and Methods: The study was carried out in 75 samples under treatment for Chronic illness in MMM hospital between age group 1 to 20 years. The samples were selected through convenient sampling technique. The Tool used for data collection and assessment of Post traumatic stress level is a Semi structured questionnaire which includes: Demographic details-: Socio demographic profile (age, gender, place of residence, religion, education, occupation, type of family etc) and .Post traumatic stress scale-Manual for the Administration and Scoring of the PTSD(Post Traumatic stress disorder) Symptom Scale - Interview for DSM-5 (PSS-I-5) Result: PTSD (Post Traumatic stress disorder) was significantly observed in all the respondents' with chronic illness. Conclusion: The preliminary study concludes the presence of post traumatic stress disorder among adolescence with chronic illness. This particularly emphasizes on multidimensional assessment and treatment.

Keywords: Chronic illness, Post traumatic stress, Adolescence

Chronic diseases are long-term medical conditions that are generally progressive. These disorder or disease compromise physical well-being, either temporarily or chronically.

\footnotetext{
${ }^{1}$ Research Scholar, Mother Teresa University Kodaikanal, Lecturer- MMM College of Health Sciences.Chennai, Tamilnadu, India

${ }^{2}$ Dean and HOD, Department of Counseling Psychology, Madras School of Social Work. Chennai; Tamilnadu, India

*Responding Author
}

Received: January 11, 2017; Revision Received: January 25, 2017; Accepted: February 2, 2017

(C) 2017 Jobson M, Subhashini R; licensee IJIP. This is an Open Access Research distributed under the terms of the Creative Commons Attribution License (www.creativecommons.org/licenses/by/2.0), which permits unrestricted use, distribution, and reproduction in any Medium, provided the original work is properly cited. 
To Determine Level of Post Traumatic Stress Faced By Adolescent Children with Chronic Illness

Epidemiological studies have shown that about 35\% of children and adolescents, on average, suffering from chronic health condition likely to suffer from Post Traumatic Stress. Post traumatic stress disorder (intrusive memories, avoidance, distress) is a condition of persistent mental and emotional stress occurring as a result of injury or severe psychological shock, typically involving disturbance of sleep and constant vivid recall of the experience, with dulled responses to others and to the outside world.

The consequences of chronic illness leading Post traumatic Stress may affect the well being of the person in turn affecting the family as a whole. This study involves to the determine level of post traumatic stress faced by adolescences suffering from chronic illness. The Key contributors of chronic illness are Poor lifestyle choices, such as smoking, overuse of alcohol, poor diet, lack of physical activity and inadequate relief of chronic stress and progression of preventable chronic diseases. These children face various health problems affecting the Physical and mental well being.

\section{Post Traumatic Stress}

Posttraumatic stress disorder (PTSD) is a common reaction to traumatic events such as assault, disaster or severe accidents. The symptoms include repeated and unwanted re-experiencing of the event, hyper arousal, emotional numbing and avoidance of stimuli (including thoughts) which could serve as reminders for the event. A sizeable proportion recover in the next few weeks or months, but in a significant group these symptoms persist, often for years. It is largely the group of people with persistent PTSD who seek treatment. For these people social and occupational functioning is often severely impaired. There are four core in PTSD which are considerably stable in all types of traumas. Such as,

1. Experiencing or witnessing a stressful event;

2. Re-experiencing symptoms of the event that include nightmares and (or) flashbacks;

3. Efforts to avoid situations, places, and people that are reminders of the traumatic event; and

4. Hyper-arousal symptoms, such as irritability, concentration problems, and sleep disturbances.

\section{Symptoms of Post Traumatic Stress}

1. Intrusive memories-Recurrent, unwanted distressing memories of the event,

2. Avoidance-Trying to avoid thinking or talking about the event,

3. Negative changes in thinking and mood,

4. Changes in emotional reactions,

5. The intensity of symptoms can vary in intensity over time. 
To Determine Level of Post Traumatic Stress Faced By Adolescent Children with Chronic Illness

RISK FACTORS FOR DEVELOPMENT OF POST TRAUMATIC STRESS DISORDER (PTSD)

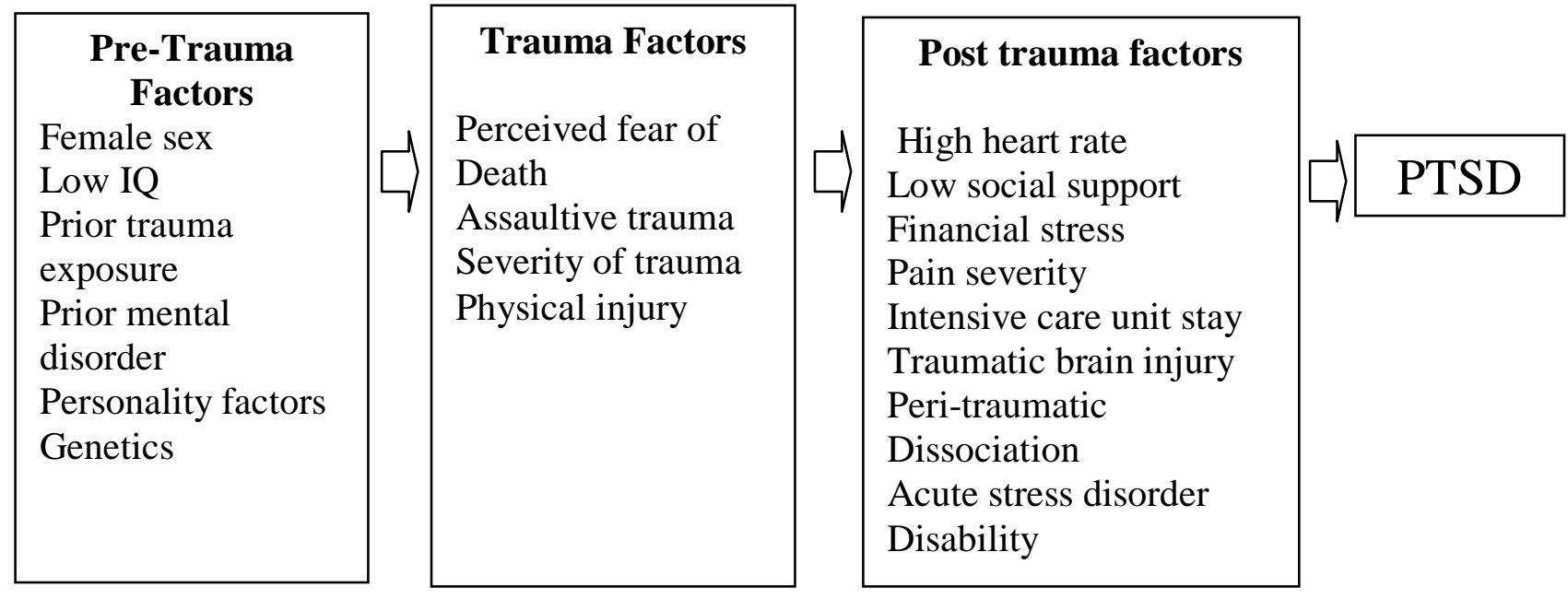

Aim:

1. This study is to determine level of post traumatic stress faced by adolescent children with chronic illness.

\section{Objectivity of the Study}

1. To assess the level of Post Traumatic Stress faced by chronic illness adolescence

2. To identify the various factors leading to Post traumatic stress.

\section{Procedure}

Children educated about the nature and procedure of the study. The children were enrolled in the study after obtaining parental consent (11-18years) / consent (18-20years). The study was conducted among 75 adolescence suffering from chronic illness. The chronic illness conditions included cardiac, neurological, diabetes and genetic condition. The tool used for data collection was segregated into two sections Section A: Socio demographic profile (age, gender, place of residence, ordinal position of child in the family, number of siblings, religion, education of parents, occupation, type of family, family monthly income) and Section B: Post traumatic stress scale- Manual for the Administration and Scoring of the PTSD Symptom Scale - Interview for DSM-5 (PSS-I-5).

1. Re-experiencing symptoms

2. Avoidance

3. Changes in cognition and mood

4. Increased arousal and reactivity

(c) The International Journal of Indian Psychology, ISSN 2348-5396 (e)| ISSN: 2349-3429 (p) | 146 


\section{RESEARCH METHODOLOGY}

\section{The Population, Sample and Sampling}

The population of this research is adolescence with Chronic illness (Cardiac, Neurology, Genetic, diabetic) of age group 11 and 20. For sampling the sample size was selected by convenient sampling.

\section{Research Tools}

The questionnaire used in this study are Section A: Socio demographic profile (age, gender, , place of residence, ordinal position of child in the family, number of siblings, religion, education of parents, occupation, type of family, family monthly income) and Section B: Post traumatic stress scale- Manual for the Administration and Scoring of the PTSD Symptom Scale - Interview for DSM-5 (PSS-I-5)

1. Re-experiencing symptoms

2. Avoidance

3. Changes in cognition and mood

4. Increased arousal and reactivity

\section{Analysis}

The data was analyzed using Statistical Package for Social Sciences (SPSS) and percentage analysis.

Research Findings

Table 1: Post Traumatic Stress Level of the Respondents

\begin{tabular}{|c|c|c|c|c|c|c|}
\hline Variable & $\begin{array}{c}\text { Not at } \\
\text { all }\end{array}$ & A little & Somewhat & A lot & Severe & $\begin{array}{l}\text { Mean } \\
\text { Level }\end{array}$ \\
\hline \multicolumn{6}{|c|}{ Re-Experiencing Symptoms } & 13.61 \\
\hline Distressing memories & - & 1(1.3) & $18(24)$ & $50(66.7)$ & $6(8)$ & 2.81 \\
\hline Nightmares & - & $3(4)$ & $10(13.3)$ & $34(45.3)$ & $28(37.3)$ & 3.16 \\
\hline Trauma happening again & - & $6(8)$ & $29(38.7)$ & $35(46.7)$ & $5(6.7)$ & 2.52 \\
\hline Emotionally upset & - & - & $13(17.3)$ & $49(65.3)$ & $13(17.3)$ & 3.00 \\
\hline Physical reactions & $1(1.3)$ & $13(17.3)$ & $37(49.3)$ & $24(32)$ & - & 2.12 \\
\hline \multicolumn{6}{|l|}{ Avoidance } & 6.04 \\
\hline Avoid thoughts & - & $2(2.7)$ & $3(4)$ & $60(80)$ & $10(13.3)$ & 3.04 \\
\hline Avoid activities, places & - & $2(2.7)$ & $20(26.7)$ & $29(38.7)$ & $24(32)$ & 3.00 \\
\hline \multicolumn{6}{|c|}{ Changes in Cognition and Mood } & 18.64 \\
\hline Trauma cannot remember & $2(2.7)$ & $11(14.7)$ & $25(33.3)$ & $23(30.7)$ & $14(18.7)$ & 2.48 \\
\hline Viewing Negative way & $1(1.3)$ & $16(21.3)$ & $29(38.7)$ & $28(37.3)$ & $1(1.3)$ & 2.16 \\
\hline Blames others, yourself & - & $2(2.7)$ & $28(37.3)$ & $36(48)$ & $9(8)$ & 2.69 \\
\hline Negative feelings & - & 1(1.3) & $9(12)$ & $43(57.3)$ & $22(29.3)$ & 3.15 \\
\hline Lost interest & - & $3(4)$ & $17(22.7)$ & $34(45.3)$ & $21(28)$ & 2.97 \\
\hline
\end{tabular}

(C) The International Journal of Indian Psychology, ISSN 2348-5396 (e)| ISSN: 2349-3429 (p) | 147 
To Determine Level of Post Traumatic Stress Faced By Adolescent Children with Chronic Illness

\begin{tabular}{|l|c|c|c|c|c|c|}
\hline \multicolumn{1}{|c|}{ Variable } & $\begin{array}{c}\text { Not at } \\
\text { all }\end{array}$ & A little & Somewhat & A lot & Severe & $\begin{array}{c}\text { Mean } \\
\text { Level }\end{array}$ \\
\hline Detached & - & $3(4)$ & $13(17.3)$ & $28(37.3)$ & $31(41.3)$ & 3.16 \\
\hline Positive feeling & $1(1.3)$ & $20(26.7)$ & $32(42.7)$ & $20(26.7)$ & $2(2.7)$ & 2.03 \\
\hline Increased arousal and reactivity & \multicolumn{5}{|l}{} & $\mathbf{1 6 . 8 3}$ \\
\hline Irritable, aggressive & - & - & $5(6.7)$ & $57(76)$ & $13(17.3)$ & 3.11 \\
\hline Taking more risks & - & $23(30.7)$ & $46(61.3)$ & $5(6.7)$ & $1(1.3)$ & 1.79 \\
\hline Overly alert, on-guard & - & $7(9.3)$ & $22(29.2)$ & $35(46.7)$ & $11(14.7)$ & 2.67 \\
\hline Jumpier, easily startled & - & $1(1.3)$ & $26(34.7)$ & $35(46.7)$ & $13(17.3)$ & 2.80 \\
\hline Difficulty concentrating & $1(1.3)$ & $3(4)$ & $26(34.7)$ & $43(57.3)$ & $2(2.7)$ & 2.56 \\
\hline Difficulty staying asleep & - & - & - & $8(10.7)$ & $67(89.3)$ & 3.89 \\
\hline
\end{tabular}

Table 1 reveals the post traumatic stress level of the respondent. The mean value of the category changes in cognition and mood is relatively high than others with 18.64. Followed by the category increased arousal and reactivity with mean value of 16.83 . the category of reexperiencing symptoms showed the mean value of 13.61 and the category of avoidance showed the least stress level 6.04.In re-experiencing symptoms nightmares were found to be high among the respondents with the mean of 3.16, avoiding thoughts were high in the avoidance category with the mean of 3.04, the respondents were feeling highly detached according to the changes in cognition and mood with the mean of 3.16 and finally respondents had difficulty in staying asleep with the mean of 3.89 in increased arousal and reactivity.

Chart No: 1 Post Traumatic Stress Level of the Respondents

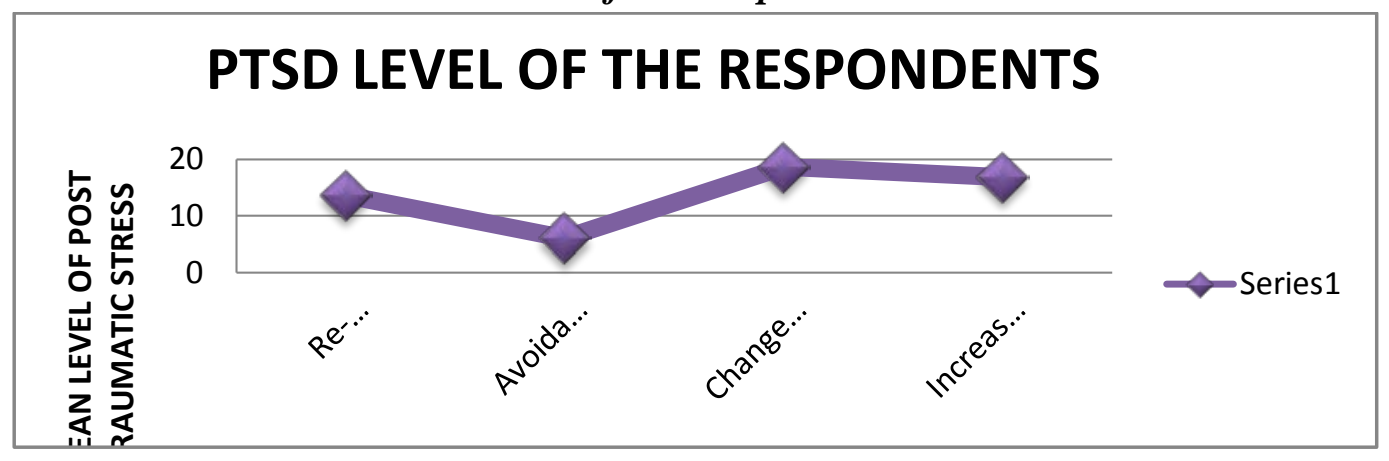

Table 2: Total Distribution of Post Traumatic Stress Level of the Respondents

\begin{tabular}{|l|c|c|}
\hline \multicolumn{1}{|c|}{ Variable } & Frequency & Percentage \\
\hline Mild & 6 & 8.0 \\
\hline Moderate & 32 & 42.7 \\
\hline Severe & 37 & 49.3 \\
\hline Total & 75 & 100.0 \\
\hline
\end{tabular}

(C) The International Journal of Indian Psychology, ISSN 2348-5396 (e) | ISSN: 2349-3429 (p) | 148 
Table 1 shows the distribution of post traumatic stress level of the respondents. Nearly half of the respondents(49.3\%) were falling under severe post traumatic stress, whereas (42.7\%) of the respondents were found to be under moderate post traumatic stress and finally only (8\%) of the respondents were found to be in mild post traumatic stress level. Stress in respondents was observed more because of the increase in their anxiety and fear after trauma.

\section{Chart No 2: Total Distribution of Post Traumatic Stress Level of the Respondents DISTRIBUTION OF POST TRAUMATIC STRESS DISORDER

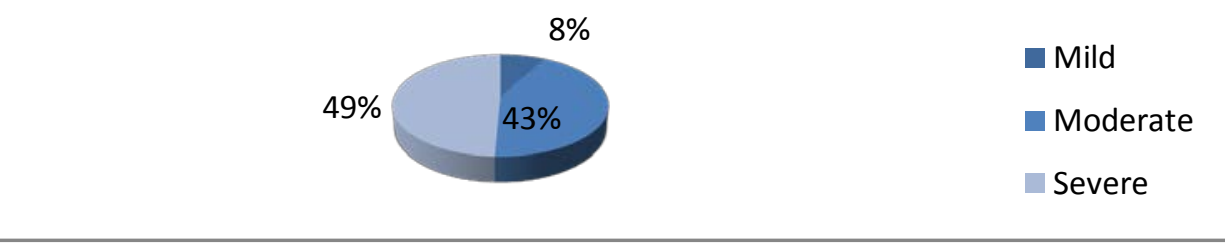

\section{DISCUSSION}

Adolescence (from Latin adolescere, meaning "to grow up") is a transitional stage of physical and psychological development that generally occurs during the period from puberty to legal adulthood. Identity development is a stage in the adolescent life cycle. For most, the search for identity begins in the adolescent years. During these years, adolescents are more open to 'trying on' different behaviors and appearances to discover who they are. In an attempt to find their identity and discover who they are, adolescents are likely to cycle through a number of identities to find one that suits them best. Developing and maintaining identity (in adolescent years) is a difficult task due to multiple factors such as family life, environment, and social status. In this stage an adolescence suffering from chronic illness tends to undergo a lot of psychological trauma which leads miserable disturbances in Normal adolescence of similar age. Adolescences are more likely to show symptoms similar to those seen in adults. They develop disruptive, disrespectful, or destructive behaviors. Older children and teens may feel guilty for not preventing injury or deaths. Since many chronic diseases cannot be cured, the main goal is to reduce the consequences of the diseases on the lives of adolescents. Identifying the associated variables influencing post traumatic stress among adolescence as early as possible can help to turn down the consequences into positive aspect through multi variation dimensional approach .Among the 75 samples analyzed in this study Majority ( 49.3\% ) of the respondents were found to be in severe Post traumatic stress disorder .(42.7) were in moderate . This percentage becomes the target respondents to develop Post traumatic Stress in mere future if multivariate approach is failed to be provided. Only $8 \%$ were in mild category which reflects around only $5 \%$ of sample is able to cope up voluntarily. 
To Determine Level of Post Traumatic Stress Faced By Adolescent Children with Chronic Illness

\section{Limitations of the Study}

1. The study was limited to only one hospital

2. Data collection was done only for a limited period of time.

3. This study was conducted on a smaller group of adolescence within a few categories of chronic conditions.

\section{CONCLUSION}

Chronic illness can lead to serious psychological consequences which in turn lead to Post Traumatic Stress Disorder. In the context, the preliminary study leading to PTSD concludes that post traumatic stress was found to be relatively high among adolescence suffering from chronic illness.

\section{SUGGESTIONS}

1. Multi dimensional and comprehensive application must be taken for people with high risk behavior.

2. Rehabilitation treatment should be encouraged and regular follow-up should be initiated.

3. Group Therapy

4. Coping strategy training programs can be initiated.

\section{Individual suggestions}

1. Talk with doctor about treatment options.

2. Engage in mild physical activity or exercise to help reduce stress.

3. Set realistic goals for yourself.

4. Break up large tasks into small ones, set some priorities, and do what you can as you can.

5. Try to spend time with other people, and confide in a trusted friend or relative. Tell others about things that may trigger symptoms.

6. Identify and seek out comforting situations, places, and people.

7. Self Caring and realizing creates difference.

\section{Practical Suggestions}

It helps to understand psychosocial consequences of chronic diseases by providing valuable information for clinicians regarding who should be screened for what kind of problems and the need for preventing these problems as part of an integrated treatment.

\section{Acknowledgments}

The author appreciates all those who participated in the study and helped to facilitate the research process.

Conflict of Interests: The author declared no conflict of interests. 


\section{REFERENCES}

Finkelhor, D., Turner, H., Ormond, R., \& Hamby. S. (2009). Violence, abuse, and crime exposure in a national sample of children and youth. Pediatrics, 124, 1411-1423.

Kilpatrick, D., et al. (2000). Risk factors for adolescent substance abuse and dependence: Data from a national sample. Journal of Consulting and Clinical Psychology, 68, 19-30.

Merikangas, K. et al. (2010). Lifetime prevalence of mental disorders in the U.S. Adolescent Comorbidity Survey Replication-Adolescent Sample. Journal of the American Academy of Child and Adolescent Psychiatry, 49, 980-988.

Kessler, R., et al (2912). Prevalence, persistence, and socio demographic correlates of DSM-IV disorders in the National Co morbidity Survey Replication Adolescent Sample. Archives of General Psychiatry, 69, 372-380.

Pynoos, R. et al. (1987). Life threat and posttraumatic stress in school aged children. Archives of General Psychiatry, 44, 1057- 1063.

Lanius RA, Vermetten E, Pain C. The impact of early life trauma on health and disease: The hidden epidemic. Cambridge, UK: Cambridge University Press, 2010.

Koenen K, Robers A, Stone D, et al. The epidemiology of early childhood trauma. In: Lanius RA, Vermetten E, Pain C, eds. The Impact of Early Life Trauma on Health and Disease: The Hidden Epidemic. Cambridge, UK: Cambridge University Press, 2010.

Costello EJ, Erkanli A, Fairbank JA, Angold A. The prevalence of potentially traumatic events in childhood and adolescence. J Trauma Stress 2002;15: 99 -112.

Yehuda R. Post-traumatic stress disorder. N Engl J Med 2002;346:108 -14.

Luthra R, Abramovitz R, Greenberg R, et al. Relationship between type of trauma exposure and posttraumatic stress disorder among urban children and adolescents. $J$ Interpers Violence 2009;24:1919-27.

How to cite this article: Jobson M, Subhashini R (2017), To Determine Level of Post Traumatic Stress Faced By Adolescent Children with Chronic Illness, International Journal of Indian Psychology, Volume 4, Issue 2, No. 87, ISSN:2348-5396 (e), ISSN:2349-3429 (p), DIP:18.01.059/20170402, ISBN:978-1-365-71287-6 